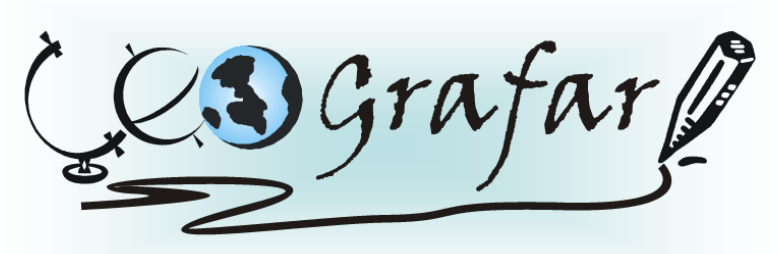

Revista Eletrônica do Programa de Pós-Graduação em Geografia - UFPR

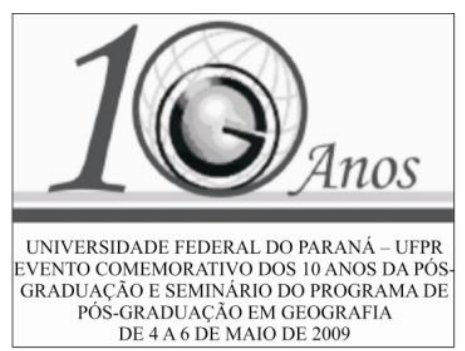

\title{
ESPAÇO TERRITORIAL TRANFRONTEIRIÇO JESUÍTICO GUARANI: O TURISMO COMO FATOR ECONÔMICO DE UNIFICAÇÃO
}

\author{
ANA SOLANGE BIESEK ${ }^{1}$ \\ MARCOS TARLOMBANI DA SILVEIRA ${ }^{2}$
}

\section{LINHA DE PESQUISA: PRODUÇÃO E TRANSFORMAÇÃO}

Este projeto insere-se no universo das pesquisas sobre o início do processo de fundação das reduções jesuítico guarani, nos aspectos históricos e geográficos, ocorridas no Brasil, Paraguai e Argentina. Os objetivos geral é identificar o espaço transfronteiriço JesuíticoGuarani na observância da economia e do poder em sua constituição, fragmentação e globalização pela atividade turística. Os objetivos específicos são: analisar o processo econômico das redes do espaço Jesuítico Guarani como elemento constitutivo territorial transfronteiriço, a desfragmentação e formação do Estado - Nação, observar os elementos fronteiriços que justificam as redes econômicas e de integração do espaço, e caracterizar o espaço territorial transfronteiriço como elemento de unificação através da atividade turística, tendo como base o Roteiro Iguassu Misiones (BR, PY e AR).

Tendo como cenário, terras argentinas, brasileiras e paraguaias, o Roteiro Iguassu Misiones é o primeiro roteiro turístico do Mercosul, uma oportunidade única de fortalecimento das relações entre os países e, conseqüentemente, de estímulo à integração entre seus povos, na busca da melhoria da qualidade de vida. Suas características conjuntas possibilitam a construção de um pólo de desenvolvimento econômico, gerando um sistema produtivo sustentável no tempo e provocando um processo endógeno de contaminação dinâmica sobre inúmeros segmentos do espaço geográfico abrangido.

\footnotetext{
1 ana.biesek@bol.com.br

${ }^{2}$ Professor orientador
} 
FIGURA 1: MAPA DA REGIÃO DAS REDUÇÕES JESUÍTICA GUARANI

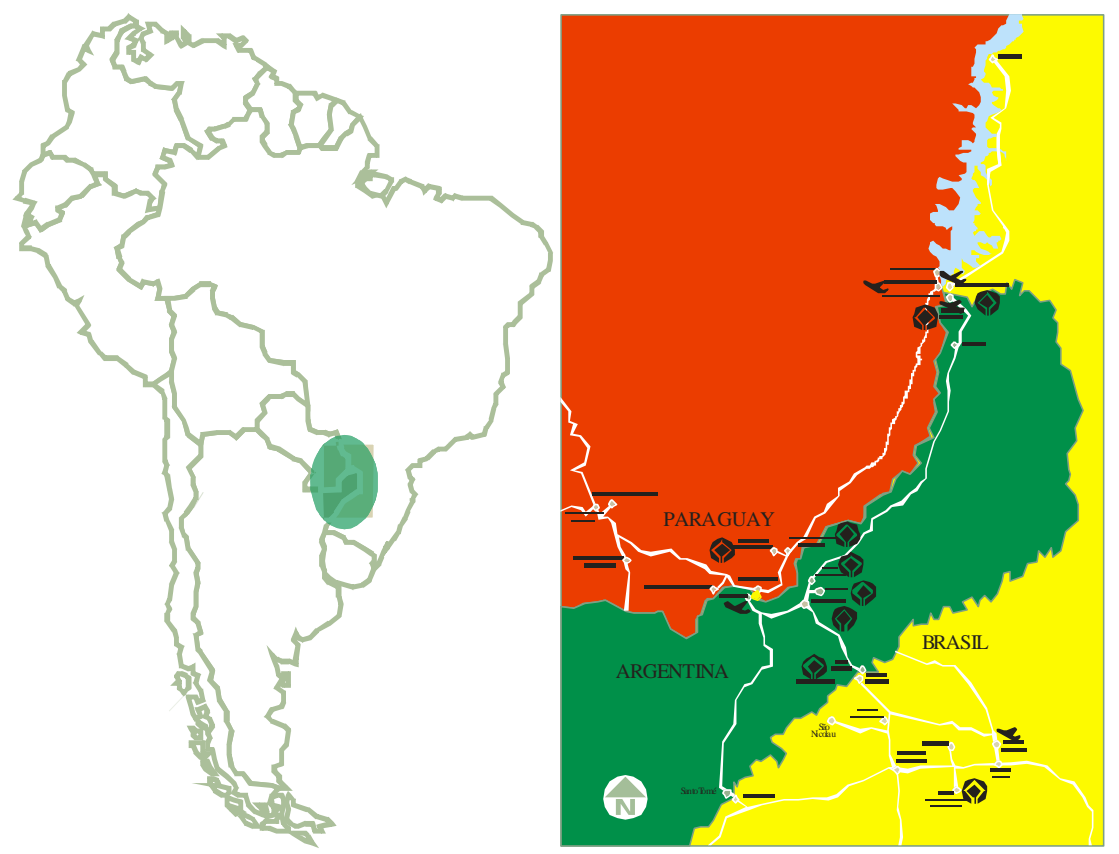

O método de pesquisa utilizado será de forma qualitativa na busca da compreensão do território das reduções jesuítico guarani, dos seus significados e dos entrevistados e para estruturação deste trabalho será destacada a pesquisa empírica do tipo exploratória, englobando levantamento documental (ou fontes primárias) e bibliográfico (ou de fontes secundárias). A fase exploratória será um dos momentos mais relevantes da pesquisa, porque representará a construção da trajetória de investigação do tema proposto para estudo.

As reduções Jesuítico Guarani foram implantadas durante os séculos XVII e XVIII nos territórios português e espanhol da América do Sul. Aproximadamente trinta missões, também chamadas de reduções, foram fundadas pela administração espanhola, nos vales dos rios Paraná e Uruguai, em território hoje pertencente ao Brasil, Argentina, Paraguai e Uruguai, onde viveram cerca de 150 mil índios guaranis. (Kern, 1994).

Segundo Reis (2000), a chamada "Republica Guarani" foi o primeiro estado industrial da América Latina, onde houve a primeira fundição de ferro, se produziram os primeiros tecidos e se iniciou a criação de gado no continente, contribuindo para a vocação econômica das regiões. A expulsão dos jesuítas em 1750 (Tratado de Madri) e as sucessivas desavenças e guerras acabaram com a Republica Guarani, restando apenas suas ruínas como testemunho de seu passado.

No Brasil, se destaca a Redução de São Miguel Arcanjo, situada na cidade de São Miguel das Missões, no Rio Grande do Sul, fundada em 1687. Tombada como Patrimônio 
Mundial e reconhecida em 1983 pela UNESCO - Organização das Nações Unidas para Educação, Ciência e Cultura, como Patrimônio Cultural da Humanidade, sintetiza o sonho dos jesuítas e guaranis de formarem uma sociedade alicerçada na solidariedade e no coletivismo. (UNESCO, 2002).

Na Argentina, destaca-se a redução de San Ignácio Mini que foi fundada em 1631 e na localização definitiva, houve um grande desenvolvimento urbano e San Ignácio hoje possui o maior conjunto urbano preservado das Missões. A igreja e o colégio foram construídos por volta de 1724 .

No Paraguai, se destaca a redução de Santíssima Trinidad del Paraná que foi fundada em 1706 com guaranis do povoado de San Carlos. Seu conjunto arquitetônico é testemunho do avanço tecnológico que alcançaram as Missões em sua última fase. Em Trinidad podem ser vistos os restos de duas igrejas, pois uma pequena igreja provisória oi construída após o desabamento do grande templo com abóbadas ocorrido em 1775.

Foz do Iguaçu, localizada no extremo Oeste do Paraná, às margens dos rios Paraná e Iguaçu, é considerado o epicentro deste roteiro, por estar estrategicamente localizado no centro desses territórios, fazendo fronteira com Paraguai e Argentina e integrando o Mercosul $^{3}$. O Parque Nacional do Iguaçu serviu como palco para a história dos guaranis, através do período de passagem quando vinham da região do Guairá se deslocando para a Argentina. Hoje, dentro do Parque nacional do Iguaçu, no espaço em que é explorado a Trilha do Poço Preto ${ }^{4}$, encontra-se protegido para estudos, lugar onde há presença de arqueologia e vestígios dos índios guaranis.

Dessa forma, percebe-se que nesses espaços, com claras fronteiras culturais, procuram fortalecer-se como um produto cultural consolidado, buscando superar qualquer diferença existente entre os países, através da união de forcas para juntos fortalecerem um acontecimento de grande contribuição na formação histórica da América Latina. É assim que o espaço, como comenta Almeida (2003, p. 72) "além de ser produto das atividades humanas, tem múltiplas valorizações e caracteriza-se por atributos funcionais, estruturais e afetivos", e

\footnotetext{
${ }^{3}$ Argentina, Paraguai, Uruguai, Brasil e Venezuela são estados membros, o restante dos paises da América do Sul são estados associados e México é estado observador.

${ }^{4}$ Localizada no Parque Nacional do Iguaçu, é uma trilha de nove quilômetros de estrada de chão que pode ser feita a pé ou de bicicleta. No final da trilha, há uma Casamata de 10 metros de altura que propicia uma vista panorâmica da mata e do rio Iguaçu. Na seqüência, uma embarcação navega pelo alto Iguaçu até o arquipélago das Taquaras, com a opção de passeio em ducks, uma versão de caiaque inflável. O percurso inteiro é acompanhado por guias experientes.
} 
na região pesquisada, deseja-se conhecer em profundidade quais são os espaços de representatividade deste povo guarani.

Os jesuítas guarani têm um sentido profundo da história. Os acontecimentos que precedem o seu mundo presente estão registrados nos aspectos da paisagem e da cultura, e cada vez que uma pessoa visita uma redução, pode lembrar as façanhas de um herói cultural, mas sem um registro escrito e um sofisticado sistema de contagem, o sentido de tempo não pode ser profundo. A dinâmica espacial desta área transfronteiriça é um desafio constante de estudos de geógrafos, turismólogos, antropólogos, sociólogos que buscam por meio da fenomenologia hermenêutica entender o espaço que traz suas raízes ligadas à presença das Reduções Jesuíticas Guarani nos séculos XVII e XVIII.

O turismo é uma alternativa importante para o desenvolvimento integrado deste território, uma vez que a região é considerada como um dos principais corredores históricoculturais internacionais do mundo. $\mathrm{O}$ pleno desenvolvimento deste potencial passa, necessariamente, pela construção de uma visão comum, uma meta clara onde se queira chegar e estabelecer os passos para alcançá-la, a partir de planos de gerenciamento e gestão integrados.

Palavras-chave: reduções, jesuítico-guarani, território

\section{REFERÊNCIAS:}

ALMEIDA, Maria. Em busca do poético do sertão: um estudo de representações. In: ALMEIDA, Maria. e RATTS, Alecsandro (orgs). Geografia: leituras culturais. Goiânia: Alternativa, 2003.

KERN, Arno Alvarez. Utopias e Missões Jesuíticas. Porto Alegre: Universidade /UFRGS, 1994 (síntese universitária 40).

REIS FILHO. Nestor Goulart. Quadro da arquitetura no Brasil. São Paulo: FAUUSP/ FAPESP, 1994.

UNESCO. Organização da Nações Unidas para Educação, Ciência e Cultura. Patrimônio Mundial do Brasil. $2^{\circ}$ ed. Brasília. Caixa Econômica Federal, 2002. 